\title{
Online communities sustainability: some economic issues
}

\author{
Laura Anna Ripamonti \\ Università degli Studi di Milano < ripamonti@dico.unimi.it > \\ Fiorella De Cindio \\ Università degli Studi di Milano < fiorella.decindio@unimi.it > \\ Mario Benassi \\ Università degli Studi di Milano < $\underline{\text { mbenassi@dsi.unimi.it }>~}$
}

\begin{abstract}
There is a growing attention being placed on community networking and community informatics, due to the role both can play in building the Information Society. Hence, the issue of the sustainability of online communities becomes more and more relevant: multiple aspects - social, institutional and economical - have to be jointly analyzed to understand how and if a project is really worthwhile. In this paper we address the economic sustainability aspect, a key component still not deeply investigated. Actually, survival and growth are common themes in the organizational and businesses literature since the beginning of the ' 60 's, nevertheless, online communities only partly comply with the available frameworks and we are left with a panorama where communities emerge and evolve as if they were either completely bottom-up, unplanned entities or rational top down quasiorganizations. Hence, our aim is to offer a first attempt to define several theoretical propositions on economical sustainability, mainly derived from our ongoing experience and research on online communities.
\end{abstract}

\section{Introduction}

ICT (Information and Communication Technology) based communities have gained a central place in recent debate among scholars and practitioners, as they seem highly appropriate for taking advantage or the potential of the technology, and for adding value to it. Communities take advantage of the potential of the technology as individuals and companies, sharing common interests, become connected in knitted webs of information exchange, in this way by-passing distances and differences. Online communities, by grouping together individuals and companies, enforce mutual trust, provide a sense of identity, and facilitate knowledge transfer and mutual learning. However, despite such perceived importance, and the growing popularity of on-line communities, the key issue of their sustainability still remains under-explored. This holds true both for not-for-profit and for-profit communities.

According to the Wikipedia ${ }^{1}$ the issue of sustainability can be broken down into three major aspects: institutional sustainability, economical and financial sustainability and ecological sustainability. Institutional sustainability involve contextual issues in supporting communities, and social issues concerning how they are structured, as analyzed by several authors (see e.g. Venkatesh, 2003; and Carroll and Rosson, 2003). Analysing the implications of ecological sustainability is beyond of the scope of this study. However, the economic and financial sustainability of online communities is a relevant issue, still not fully addressed (as reported also in Millen, Fontane and Muller, 2002), in spite of its fundamental importance - either for practical or conceptual reasons - for any online community.

\footnotetext{
${ }^{1}$ http://en.wikipedia.org/wiki/Main_Page
} 
Since no specific study fully addresses this issue, we will try to import - where possible - useful concepts and models from Management and Economics literature, adapting these to the specific context of online communities, both for and not-for profit.

Business scholars and business literature in general maintain that communities are beneficial for business, but this judgment is based upon anecdotes at best. Despite some good, in-depth case studies (such as on Ebay and Amazon), bearing evidence to the positive influence of a trustworthy, selfreinforcing community on firms' competitive position (Armstrong and Hagel, 1998), most literature and scholars consider communities as no more than a mere social or cultural issue. The most popular view is that they, at a maximum, may provide a favorable context in the society (this is the case, e.g., of community networks - CNs) or somehow help companies by making their task environment more munificent (in the case of online business communities).

More recently, scholars have paid increasing attention to communities and made them a crucial unit of analysis for addressing old issues in new ways. For instance, Fiol and O'Connor (2002) draw lessons on radical change processes affecting communities and show how the interaction between hot emotional interpretations and cold cognitive interpretations make change possible. From a different, more business-oriented perspective, Von Hippel (2001) suggested that communities of users may play a crucial role in the innovation processes by making crucial information freely available to manufacturers, and even by creating and sustaining complex innovations without any manufacturers' involvement.

Along the same vein, Lee and Cole (2003) explored how communities of programmers developed new knowledge by working together in a public, dispersed environments, where everybody is connected to everybody else through the net. They showed convincingly through the examination of the Linux case-study how open criticism and error correction worked as a genetic rule to make development of the community possible and for making the whole development possible.

Although related to different knowledge domains, these studies show that communities do have specific features and that their evolution over time, as well as their outcome, calls for a reconsideration of concepts normally used in the management literature.

Communities are not a novelty in the scientific debate, but their use in the business literature is quite new. Up to only a few years ago, most popular theoretical models depicted firms as stand alone islands, and did not pay attention to the knitted web of relationships in which they were embedded. Studies by scholars working across different disciplines showed, on the contrary, that relations can make a difference in the usual business domains, be it the competitive strategy of the firm, its learning processes or more generally its ability to cope with volatile environments.

Moreover, relationships among professionals working inside a firm or in different firms have been shown to matter and this is even more relevant when patterns of interactions are repeated over time, a collective identity appears and common goals are present. Communities are such a case: in a community, although participants may fluctuate, there is a stable number of actors working on common issues. Examples of well-documented communities are Orr's community of technicians fixing problems at Rank Xerox, or Lee and Cole community of Linux developers (Orr, 1990; Lee and Cole, 2003).

Online communities are a special case, for - holding true the above features - interactions occur primarily online and actors may not necessarily know each other. This is the case of citizens interacting online on shared issues, but also of users (customers, employees, partners, etc.) interacting with their company, among themselves to discuss products' features or to launch promotional initiatives, to suggest improvements and so on. Not only are studies on economical and financial sustainability lacking even for for-profit online communities, but also no sound cost-benefit analysis of online communities from the companies' standpoint currently exist in the literature.

Online communities may reinforce companies' visibility and strengthen customers' retention, but they also result in costs, require commitment and skills and companies often take for them granted. Not surprisingly, while their launch is often a-critically supported, disinvestment decisions will normally made when financial problems arise. Most companies are suspicious, adopt a wait and see approach, while others embrace communities with no clear understanding of their pros and cons.

By offering propositions on the issue of sustainability, we do hope to offer scholars and practitioners useful insights for planning and managing online communities that will support their institutional goals, both in for-profit and not-for-profit organizations. 
Building a general sustainability model is a long and complex process; hence, in this paper, we will only tackle two issues we consider to be crucial: how to define the cost structure of online communities and how to measure their benefits. To do that, we will first define a prototypical model ( $\S$ 2) on the basis of concepts derived from Management Sciences. Actually, even if the business literature at the moment has no off-the-shelf solution to offer, basic concepts on cost and benefit evaluation can be effectively adapted to the specific case, as for example, in designing a framework general enough to guide promoters in developing their own strategies for assuring the economical sustainability of their communities.

In the second part of the paper ( $\$ 3$ ) we analyse the RCM - Rete Civica di Milano (Milan community network) case, in order to share several lessons on strategy building for online community economical sustainability.

\section{Issues on sustainability: how to evaluate online communities' costs and benefits}

Although online communities are not a recent phenomenon - they were active before the Web - a general, commonly agreed-upon, definition still does not exist (see, e.g., Preece, 2000). Also, communities are strange animals, for their birth and evolution has taken scholars by surprise: they have just began exploring how communities may be born (see e.g. Preece, 2000 and Kim, 2000) what their benefits are, how they evolve over time, and how they can be socially sustainable (see e.g. De Cindio et al., 2003). But we as yet haven't tackled the financial and economic aspects of their sustainability. We do maintain that these issues are very relevant both for profit and not for profit organizations, and we believe that a general model of sustainability would be highly beneficial. If such a model existed, institutions and citizens could realize the economic and financial benefits of building and managing a community; while companies, on the other hand, could become aware of the managerial and organizational "technology" needed to build and maintain a community.

As a first step we will assume that online communities (of any kind), according to their sociotechnical nature (Preece, 2000), are organizational subjects, and thus endowed with a precise life-cycle (Wenger et al., 2002). Usually online community start-up requirements and related costs are not problematic to define, for community's promoters normally do know the socio-technical needs of their project, how related costs may be covered, and which benefits it is possible to realize in the first phases of the community life. Suppose for instance a company is willing to set up a temporary community, say for gathering feedback about a new product: in this case, tangible and intangible inputs are easily definable, and comparable with the value of the information the company has already acquired. This example is clearly fictional: companies and organizations in general do not set up "temporary communities", and their outcome is not easily pre-definable. Although we recognize initial stages are very important and cannot be overlooked in a general model of sustainability, we will focus on the economical sustainability of subsequent life-stages, with a particular attention on the maturity period of a community, that is to say when a "significant" number of members has been reached.

Simply put, a process, activity and organization is sustainable to the extent the inputs and outputs are in balance. Online communities should be seen as investments with medium to long term benefits. Although some of these benefits may be economic in nature - for example: technicians may devise methods to cut the maintenance costs of complex products - traditional, firm-based and marketoriented variables are not appropriate: in a community, there is inconsistency between the value of inputs and outputs. In communities inputs bear costs, and can be estimated, whereas outputs are for the most part intangible and difficult to value. How for example, could a company (but the case of a local not-for-profit is basically similar) use a pure P\&L (Profit and Loss) or budget-like approach in evaluating the increase in customers' brand awareness due to participation in a community of supporters, the new knowledge realized about hidden features of its products' portfolio, or the new applications users were able to devise?

Benefits cannot be too vaguely or ex-post assessed: a naive, short-sighted "let's invest and then will see what happens" approach does not hold possible. On the other hand, organizations should pay attention not to be locked in a too specific, revenue-like evaluation approach. Only a wise performance measurement assessment can help organizations to understand benefits of communities and to strike a right balance between costs and benefits.

By focusing on the cost drivers and benefits indicators of online communities, we want to tackle the sustainability issues from a wider perspective. As the life and success of any (for-profit and not-forprofit) online community depend on a complex mix of multidisciplinary aspects (see, e.g., Kim, 2000; Preece, 2000; Ripamonti, 2004), a good starting point can be the definition of critical success factors 
(CSFs) which most heavily affect an online community's sustainability. Once CSFs are clear, a path for defining the appropriate cost structure of each online community, based on a rigorous assessment of resource requirements, can be built (see Fig.1). The same list can be also used for assessing benefits. The comparison between cost drivers and benefits measurement can be helpful in selecting appropriate strategies for sustainable communities.

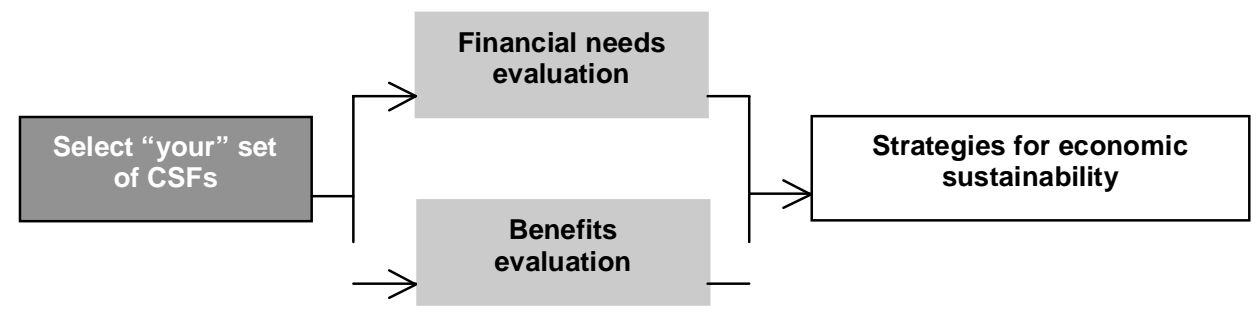

Figure 1 - The process for determining sustainability strategies

Cost and benefit evaluation for an online community are associated with a selected number of critical success factors e.g., following Wenger et al.'s (2002) classification (see Tab.1). Although Wenger's list is specially addressed to Communities of Practice (CoPs), they share with online communities a great deal of features (cfr. De Cindio \& Ripamonti, to appear), thus we think they could be a good starting point for our analysis.

CRITICAL SUCCESS FACTOR TO BUILD COMMUNITIES

\begin{tabular}{|c|c|c|}
\hline Factors & Technolog & cal implications \\
\hline $\begin{array}{l}\text { 1. Presence } \\
\text { and } \\
\text { visibility }\end{array}$ & $\begin{array}{l}\text { - } \text { pointers } \\
\text { - } \text { community directories } \\
\text { - } \text { push distributions (newsletter, reminders, ...) } \\
\text { - member directories }\end{array}$ & $\begin{array}{l}\text { - who is doing what } \\
\text { - } \text { presence awareness } \\
\text { - instant messaging } \\
\text { - virtual coffee }\end{array}$ \\
\hline 2. Rhythm & $\begin{array}{l}\text { - } \text { community calendar } \\
\text { - } \text { reminders } \\
\text { - synchronization of calendars } \\
\text { - } \text { synchronous events }\end{array}$ & $\begin{array}{l}\text { - } \text { invitations } \\
\text { - minutes of events quickly available } \\
\text { - hot topics }\end{array}$ \\
\hline $\begin{array}{l}\text { 3. Variety of } \\
\text { interactions }\end{array}$ & $\begin{array}{l}\text { Asynchronous: } \\
\text { - email and discussion boards } \\
\text { - document check-out/version control }\end{array}$ & $\begin{array}{l}\text { Synchronous: } \\
\text { - lectures and large meetings } \\
\text { - application sharing } \\
\text { - Web tours }\end{array}$ \\
\hline $\begin{array}{l}\text { 4. Efficiency of } \\
\text { involvement }\end{array}$ & $\begin{array}{l}\text { - } \text { integration with work systems } \\
\text { - personalized knowledge/application portals } \\
\text { - subscriptions }\end{array}$ & $\begin{array}{l}\text { - tours of new activity } \\
\text { - content filtering and ordering } \\
\text { - archiving of interactions }\end{array}$ \\
\hline $\begin{array}{l}\text { 5. Short term } \\
\text { value }\end{array}$ & $\begin{array}{l}\text { - mechanisms for asking questions } \\
\text { - FAQ's }\end{array}$ & $\begin{array}{l}\text { - Intelligent access to experts } \\
\text { - Help forums }\end{array}$ \\
\hline
\end{tabular}




\begin{tabular}{|c|c|c|}
\hline & - Databases of answers & - $\quad$ Brainstorming facilities \\
\hline $\begin{array}{l}\text { 6. Long term } \\
\text { value }\end{array}$ & $\begin{array}{l}\text { - Repositories for artifacts } \\
\text { - Taxonomies } \\
\text { - Search mechanisms }\end{array}$ & $\begin{array}{l}\text { - Discussing and updating a learning agenda } \\
\text { - Spaces for practice-development projects }\end{array}$ \\
\hline $\begin{array}{l}\text { 7. Connections } \\
\text { to the world }\end{array}$ & $\begin{array}{l}\text { - News } \\
\text { - External events announcements } \\
\text { - Directory of external experts }\end{array}$ & $\begin{array}{l}\text { - Links to other sites } \\
\text { - Library of references }\end{array}$ \\
\hline $\begin{array}{l}\text { 8. Personal } \\
\text { identity }\end{array}$ & $\begin{array}{l}\text { - Profiles } \\
\text { - Synchronizing profiles across communities } \\
\quad \text { with multiple view } \\
\text { - Reputation and ranking }\end{array}$ & $\begin{array}{l}\text { - } \\
\text { - } \text { Preferences } \\
\text { - } \quad \text { Private places }\end{array}$ \\
\hline $\begin{array}{l}\text { 9. Communal } \\
\text { identity }\end{array}$ & $\begin{array}{l}\text { - Having and furnishing a communal place } \\
\text { - Public access to community's "source } \\
\text { documents" }\end{array}$ & $\begin{array}{l}\text { - News about the community and success stories } \\
\text { - Distinctive look and feel } \\
\text { - Community public presence }\end{array}$ \\
\hline $\begin{array}{l}\text { 10. Belongings } \\
\text { and } \\
\text { relationships }\end{array}$ & $\begin{array}{l}\text { - } \text { Personal profiles } \\
\text { - Supporting private interactions and } \\
\text { interpersonal relationships }\end{array}$ & $\begin{array}{l}\text { - Conversations online to help the "shyest" } \\
\text { - Chat moderators }\end{array}$ \\
\hline $\begin{array}{l}\text { 11. Complex } \\
\text { boundaries }\end{array}$ & $\begin{array}{l}\text { - Differential access rights } \\
\text { - Lurking facilities } \\
\text { - Public areas and restricted ones }\end{array}$ & $\begin{array}{l}\text { - } \text { Subspaces } \\
\text { - } \quad \text { Nested features }\end{array}$ \\
\hline $\begin{array}{l}\text { 12. Evolution: } \\
\text { maturation } \\
\text { and } \\
\text { integration }\end{array}$ & $\begin{array}{l}\text { - Low initial investment (money) to have a } \\
\text { "tentative" commitment } \\
\text { - Enough feature for future development }\end{array}$ & $\begin{array}{l}\text { - Flexibility in configuration } \\
\text { - Ongoing reflection, assessment and redirection }\end{array}$ \\
\hline $\begin{array}{l}\text { 13. Active } \\
\text { community } \\
\text { building }\end{array}$ & $\begin{array}{l}\text { - Logs and statistics } \\
\text { - Polling and voting } \\
\text { - Assessment tools and surveys }\end{array}$ & $\begin{array}{l}\text { - Administrative help and reminders } \\
\text { - Switches and policy enforcements algorithms } \\
\text { - Health indicators }\end{array}$ \\
\hline
\end{tabular}

Table 1 - CSFs affecting community building according to Wenger et al. (2002)

As a first step, it is necessary to contextualise Wenger's list, selecting the subset of CSFs most directly relevant for each specific community, as not all of these have the same importance in different contexts (e.g. "integration with the work system" in factor number 4, probably will not be crucial for a citizens network, as well as "chat moderators" in factor number 10 may be quite irrelevant in organizational knowledge sharing communities).

As a second step, selected factors (and related socio-technical features) should be translated into specific resource requirements. For example, if the presence of "chat moderators" is considered a distinctive feature, it should be necessary to provide both personnel skilled in moderating chats and a technical infrastructure that supports chats. Once all the features are translated into resource requirements (e.g. specific skills for the personnel, technical features, hardware, software, buildings, internet connection, etc.) costs can be attached to each of these, and thus a total cost - and the consequent financial need - can be estimated (see Fig.2). 


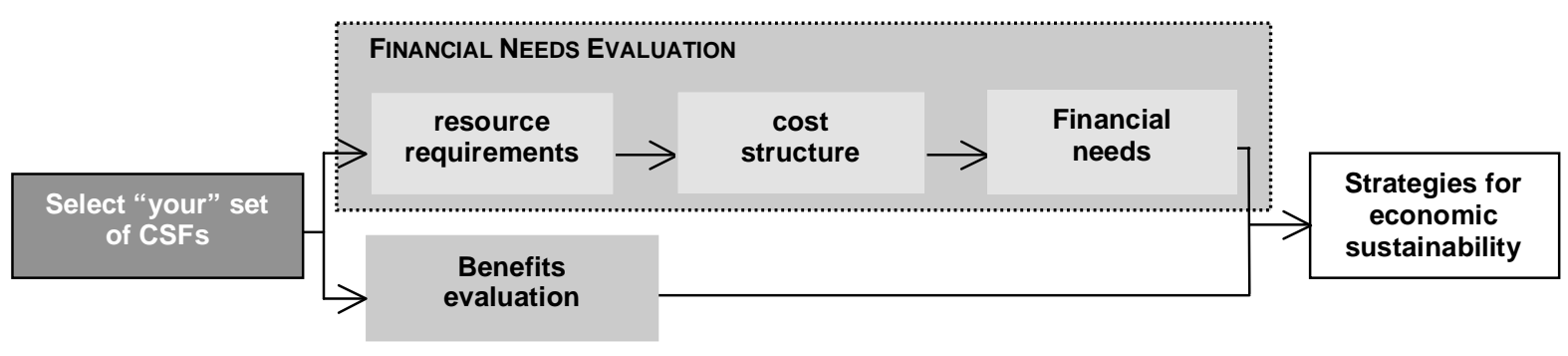

Figure 2 - Financial needs evaluation process

These steps are not enough. We also need a means for demonstrating to the actors involved in the community project (e.g. local bodies, members of the community, organizational subjects, etc.) the value of the investment - since it produces benefits - for example, for asking a public body to economically sustain a community network, or for justifying to the top management that the community-based intranet we are managing should be considered in the next year's budget. This is even more important if we are endowed with the power of deciding our own strategies (that is to say we are the community promoters): comparing financial needs and benefits of our community can help in developing a framework to design strategies for achieving the economic sustainability of the community.

We are talking of "benefits" and not of "revenues", since most online communities (and especially community networks) usually are not intended for "selling" something, and therefore a cost-revenue analysis should be substituted by a more appropriate cost-benefit analysis. Hence, the key issue for communities is producing useful benefits, no matter whether they are or are not tangible. To make a community sustainable, benefits should out-weigh costs in the long run: online communities are generally long-term investments, able to generate a perceivable benefit only after a considerable amount of time. Time is necessary for consolidating interpersonal relations and achieving a critical mass of members.

The performance of communities and benefits evaluation is far from "consolidated": subjective biases may severely limit actors outside the organization or too far away from its daily working to understand the benefits (see Wenger et al., 2002). Wenger's CFSs list could be of some help for evaluating benefits of both for and not-for-profit online communities, since it supplies an effective mean for directly linking critical socio-technical features and requirements - typical of an online community - to evaluation criteria for benefits and performances- typical of a managerial approach. Fig.3 summarizes a possible path for evaluating an online communities' benefits and performances starting from Wenger's CSFs.

Since detailed socio-technical requirements that affect the success of an online community cannot be "immediately" translated into something meaningful from a managerial point of view, we suggest Wenger's CSFs be grouped into four "macro areas" (see Tab.2): "learning”, "identity", "innovation", "effective structure" which are all relevant for any organization, and also crucial issues for any community. For example, Ducati - a famous Italian motorbike manufacturer - has leveraged online community for reinforcing its brand image, thus positively affecting both identity and innovation. Similar considerations can be done for the Open Source movement, but this holds true also for online communities of self-organizing citizens.

Thinking of benefits from these viewpoints is easier, and qualitative and quantitative measures can be identified for tracking online communities' performances. 


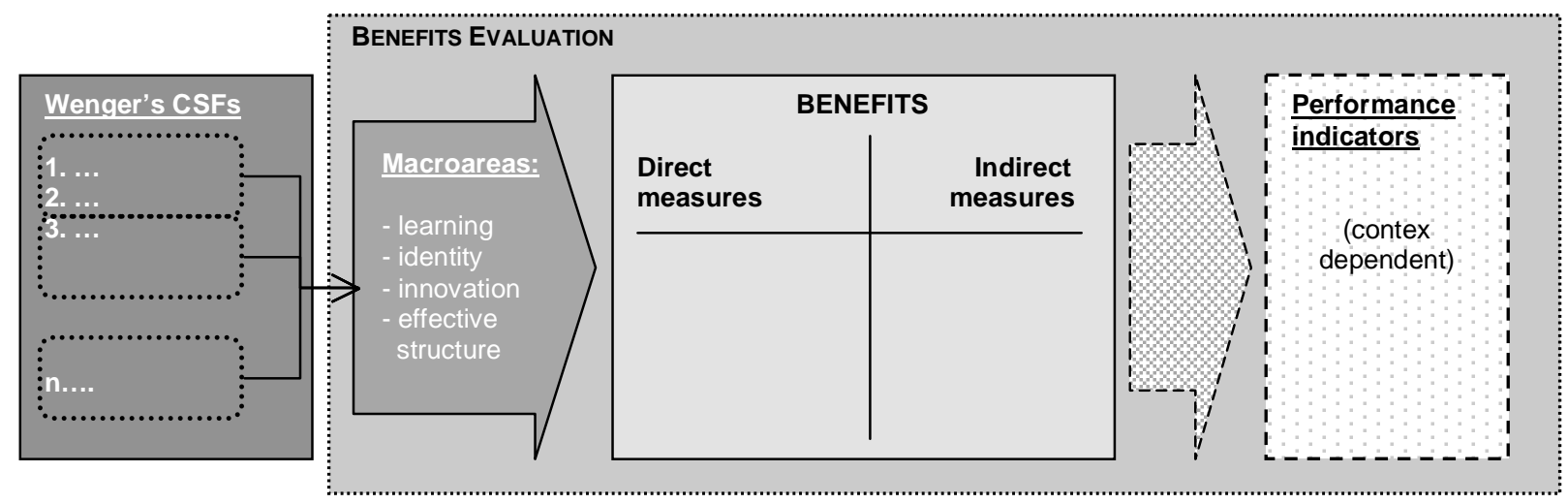

Figure 3 - Benefits evaluation process: from Wenger's CSFs to performance indicators

\begin{tabular}{|c|c|}
\hline MACRO-AREAS & ASSOCIATED WENGER'S CSFS \\
\hline Learning & $\begin{array}{l}\text { 5. short term value } \\
6 \text {. long term value }\end{array}$ \\
\hline Identity & $\begin{array}{l}\text { 1. presence and visibility } \\
\text { 2. rhythm } \\
\text { 8. personal identity } \\
\text { 9. communal identity }\end{array}$ \\
\hline Innovation & $\begin{array}{l}\text { 7. connections to the world } \\
\text { 12. evolution: maturation and integration } \\
\text { 13. active community building }\end{array}$ \\
\hline Effective structure & $\begin{array}{l}\text { 3. variety of interactions } \\
\text { 4. efficiency of involvement } \\
\text { 10. belonging and relationships } \\
\text { 11. complex boundaries }\end{array}$ \\
\hline
\end{tabular}

Table 2 - mapping Wenger's CSFs to macro-areas

Defining measures for learning, identity, innovation and effective structure is not a trivial exercise, but management literature and companies' experience could offer several hints. Measures can be twofold: direct and indirect. Direct measures weigh the impact of an online community on one of the macro-areas listed above: for instance, online communities may be beneficial in devising new ways of solving specific problems (macro-area: learning), in lowering turn-over rates (macro-area: identity), in cutting time to market (macro-area: innovation) or in lowering coordination costs (macro-area: effective structure). Indirect measures influence online communities' side-effects on other goals: for instance Shell has developed an online community of practice for its technicians aimed at sharing knowledge and solving problems. This may have affected areas of innovation and learning. Hence an increase in innovative ideas or in personal expertise should have been expected and measured (e.g. monitoring the increase in the number of new projects and ideas proposed by a research team). Nevertheless the system also demonstrated that it would be helpful in cutting costs related to solving complex problems.

Measures can become very precise: for example, organizations using balanced scorecard methods (Kaplan and Norton, 1996) may derive new appropriate performance indicators to be included in the set they normally adopt. In this case, it should be remembered that the choice of appropriate 
performance indicators (sketched with a discontinuous line in Fig.3) is strongly context dependent, as it is affected by the specific monitoring system (if any) adopted by the organization, by the goals and mission of the online community and by the macro-areas involved with the community activities.

Once both cost structure and benefits measurement are set, the online community management can define strategies that are appropriate for covering a community's financial needs, as we shall see in the RCM case study. Defining these strategies is a key element in pursuing the mission and goals of the community, and thus a way of avoiding the risk of denaturalizing it (having the community lose its essential nature). This is precisely what happened to the Amsterdam Digitale Stadt (DDS), where in order to fund the basic non-profit activities, DDS signed several consultancy contracts and hired personnel, generating a vicious circle: a bigger staff forced the organization to accept more and more contracts to cover personnel costs, thus slowly transforming the former DDS into a software consultancy firm like many others (Lovink and Riemens, 2004).

Generally speaking, the strategies of online communities of for profit organizations should be coherent with the overall missions and goals of the company. Along the same vein, sticking with the mission of a not-for-profit online community means selecting activities coherent with the purposes of the community, thus reinforcing the community's essential nature through innovation, a sense of identity, etc. (for example RCM refused to act as an Internet Service Provider and host for private web sites for generic customers, while it accepted to supply the same services to non-profit associations and small businesses, as they are target partners in the RCM mission).

\section{The RCM case}

RCM was born in September 1994, as an initiative of the Community Informatics Laboratory (LIC) of the University of Milan. One of RCM's major goals was to give citizens the chance to shape the Information Society by supporting (with ICT) the spontaneous initiatives of individuals and groups of citizens (see De Cindio, 2004), and by developing appropriate enabling technologies. Since RCM is still alive and prospering after ten years of activity (while so many other similar CNs have ceased to exist), it can thus be considered as a "best practice" case study among not-for-profit online communities.

RCM'S COST STRUCTURE

COST-CONTAINING ACTIONS

1. technical infrastructure:

a. high-quality connection;

b. hardware (server and personal computers);

c. software (servers and application software)
- cooperation with local public bodies;

- $\quad$ partnerships with business subjects;

- developing projects

- $\quad$ Skilled personnel with multidisciplinary background

a. technical competences;

- $\quad$ Flexibility

b. managerial competences;

- University resources (e.g. students)

c. legal competences;

d. social competences;

e. secretary.

3. overhead:

- Involvement of the University
a. commodities;
b. consumables;
c. etc.

Table 3 - RCM's cost structure and actions undertaken to lower financial needs 


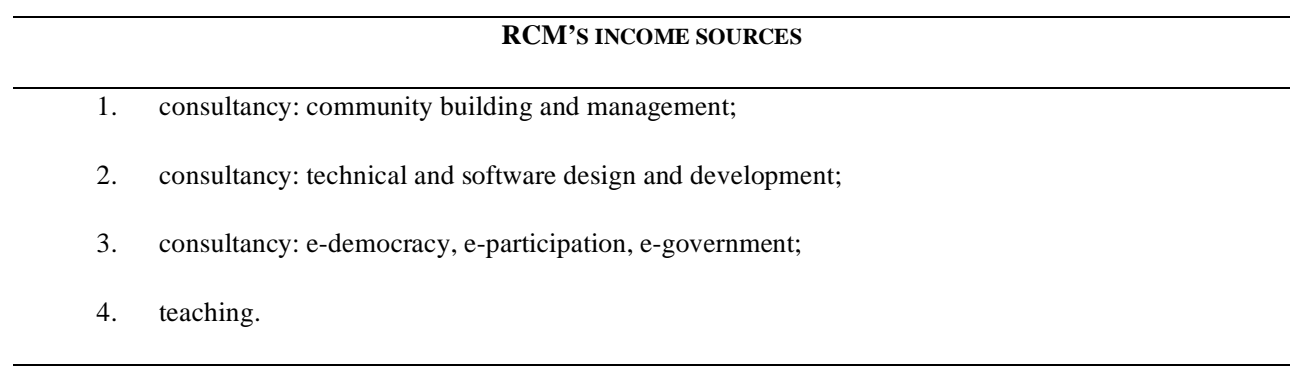

Table 4 - RCM's revenue sources

Since no off-the-shelf sustainability model existed, RCM followed an adaptive approach to assure its survival during the last 10 years, starting from scratch and continuously adjusting its actions in response to specific needs. This meant that there was cost containment (see Tab.3) coupled with income sources consistent with RCM's goals (see Tab.4). This behavior was adopted outside of any kind of business model: actually the whole development of the $\mathrm{CN}$, in all its different phases, has been - quite implicitly - based on the Community Centered Development model (CCD - see, e.g., Preece, 2000). This approach meant constantly putting the focus on the community members' needs, and routing RCM's mission and goals toward what its members perceive as a "value" (see De Cindio et al., 2003). To achieve this goal RCM decision-makers involved community members (with a bottom up approach) even in the definition of the mission statement, and in several choices with regard to technological improvements. This meant both defining technical requirements and measuring performance on the basis of the utility perceived by the community members, in this way sticking to something that we may call "an implicit CFSs list".

\section{Costs structure and performance measurement}

By and large, two major categories of resources are needed for running an online community: an appropriate technical infrastructure and skilled personnel. The structure of these costs varies according to the technical and skill requirements related to the specific community: in order to implement Wenger's CSFs, or at least a scalable subset of them, a well-balanced mix between technical and sociomanagerial resources would need to be used. Actually, technical features alone are insufficient to guarantee successful and useful interactions among community members,; in addition, even a strong commitment from the community staff will be useless, unless supported by an appropriate technological environment (the importance of a joint design of socio-technical aspects is constantly debated - see, e.g., Preece, 2000). Last but not least, a certain percentage of standard overhead costs (furniture, telephones, stationeries, fax, etc.), should be added to the total amount.

\section{Technical infrastructure costs}

The technical infrastructure includes: servers (both hardware and software) with a high-quality connectivity and related services (e.g. security, availability, robustness, etc.), personal computers and application software. All these costs vary little relative to the "volume" of the services offered, thus the whole set of these costs can be defined as fixed infrastructure costs. Such a technical structure is not at all a "cheap" investment. Special attention should be paid to the choice of an appropriate community server, since its features, flexibility, performance and scalability will heavily influence both the development of the community and the management/technical administrative activities. As many as possible among Wenger's CSFs should be - at least potentially - supported by the features of the selected platform. The RCM community environment relies mainly on a FirstClass server, which potentially covers well the requirements for $1,2,5,7,8,9,10,11$, and 12 of the CSFs, while it is a little lacking in supporting "synchronous interactions", "integration with other applications", and "tools for assessment and health indicators".

\section{Personnel costs}

Generally, for a $\mathrm{CN}$, the most relevant drivers in the cost structure is represented by personnel: to run an online community, appropriately skilled and trained personnel with multidisciplinary competences are required. And this means appropriate wages and commitments. 
Many CNs (as well as many online communities) begins with a small, but very committed, staff, often corresponding to the $\mathrm{CN}$ promoters. As time goes by, either some among the founders leave, or the $\mathrm{CN}$ grows, inducing a growth in staff (and thus costs). This also is, is what happened to the Amsterdam Digitale Stadt (DDS).

In order to avoid this risk, RCM always kept its staff at the smallest level possible, and developed a network of professionals which would cooperate with RCM on specific projects as required.

\section{Overhead costs}

Although overhead costs - in general - should be minor compared to those deriving from the sociotechnical infrastructure, nevertheless they have a very relevant impact on the overall cost structure, since they are continuous in time: for example, hiring an office in Milan would have been impossible for RCM, since too costly. Thus, as we shall see, RCM set up partnerships with public and private subjects.

\section{Performance measurement}

The problem of understanding if and why community members (and, more generally, community stakeholders, such as public and private partners) were or were not satisfied by the RCM environment and services arose quite early in the CN's life. Both social (e.g. adopting different policies for moderating different types of forums) and technical (e.g. creating ad hoc systems for elaborating statistical data from log files - cfr. Longhi, 2000) solutions have been developed, over the years, to monitor the virtual life of the community. This process evolved through trial and error and still goes on, since, at the moment, no definitive tool exists for systematically monitoring virtual interactions, nor any explicit relation between a specific list of CSFs and monitoring outcomes or results has yet been traced for RCM.

\section{Strategies for sustainability and the importance of being a participatory foundation}

The next step in our prototype model requires the definition of appropriate strategies for guaranteeing the economic sustainability of the online community, on the basis of a comparison between performance and financial needs. Although RCM has not as yet developed any systematic performances measurement system, feedback from its members' and stakeholders' (in term of use, new projects, participation, ideas, funding, etc.) supplies evidence that the $\mathrm{CN}$ is perceived as something useful, and thus worth maintaining. Hence we will now describe the strategies RCM adopted for covering its financial needs and assuring its sustainability.

\section{Strategies for containing fixed infrastructural costs}

In general, several strategies to contain the expenses of a $\mathrm{CN}$ could be envisaged, such as:

- $\quad$ cooperating with public bodies (e.g. universities or public libraries, a better choice than local governments in guaranteeing independence from political games); or

- negotiating partnerships with reliable and far-seeing commercial Internet Service Providers (for example, the ISP can "improve its image" by stressing its attention toward social issues and Digital Divide problems). While selecting partners, it is important to favor actors able to guarantee the preservation of the CN's independence.

By adopting the second solution, RCM reduced its costs, while providing high-quality connectivity, despite the fact it is located at the university. Actually Universities - in Italy as is often the case elsewhere - is only allowed to use their network infrastructure for educational purposes: hence, while RCM falls fully into this category, some of its initiatives (e.g. providing services to small businesses) may be more questionable. RCM has also set up cooperation with several ICT companies, which donate some hardware.

\section{Strategies for containing personnel costs}

According to the RCM experience, in order to keep the staff small (while providing an adequate coverage of the required skills and high-quality services), the following competences at least are necessary:

- technical: both for infrastructure management (web-based technologies, security, etc.) and for computer-mediated communication (Human Computer Interfaces, Computer Supported Cooperative Work, Participatory Design, etc.); 
- social: for an appropriate handling of the social aspects (promoting a sense of cooperation within the community, envisaging critical situations, understanding community dynamics, monitoring community evolution, etc.);

- legal: this is a crucial issue. Actually, in the RCM case, not only "standard" legal issues (privacy laws, copyrights, etc.) have been addressed, but also "subtler" problems, such as: guaranteeing the right of free expression for everybody (while preserving a polite and fair discussion environment), balancing the requests of all the community components (which may have different opinions and goals), negotiating partnerships (while preserving RCM nature and goals), etc.;

- managerial: both for managing the $\mathrm{CN}$ itself and its projects. Project management skills are crucial for at least three reasons: a $\mathrm{CN}$ is an always evolving project; the $\mathrm{CN}$ members' projects often need an "enabler" for being developed, and activities related to revenue sources need to be correctly handled .

However, this set of competences does not necessarily need a one-to-one mapping with staff members. Actually, the RCM staff, whose composition has been quite stable for several years, consists of ${ }^{2}$ :

- a community manager (a free lance computer professional), who is also the Director of the RCM Foundation - hence he deals with managerial issues as well;

- a webmaster and a system administrator (both free-lance computer professionals);

- $\quad$ a half-time secretary (the only employee of the RCM Foundation);

- one-full time equivalent project manager: that is to say two professionals, both at half-time and paid on a project basis. One of them has a managerial background and supports partnership negotiation;

- a part-time legal consultant (free lance lawyer);

- $\quad$ several "newly-degreed" students: they are involved occasionally for carrying on specific projects.

Social competences and/or sensibilities are not explicitly mentioned here, as they are spread throughout the whole staff (including as to specific backgrounds, experiences and/or personal skills).

A relevant role is played also by the RCM founder: she acts both as a manager and as a project leader, without being explicitly "paid" for this. Since she is a professor and RCM is the main initiative of the Civic Informatics Laboratory, this can be seen as a major funding by the University. Besides competences and roles, it is worth noting that RCM is managed as a kind of cooperative: people's wages are discussed within the staff while preparing the budget, and when necessary, RCM allows some staff members to accept external jobs (mainly teaching, at the University or elsewhere). Instead of impoverishing RCM, the outcome of these external activities sets up new and productive relationships.

\section{Strategies for containing overhead costs}

RCM's office, together with its furniture, electrical power, telephones, faxes, etc. were the basic funding provided by the University. However, the advantages for RCM of being located at the University cannot be reduced to costs cut (De Cindio, 2004). On the other hand, the University got more "visibility" in the local community and the possibility of exploiting RCM skills and experience in developing effective online interactions for example, launching the "University Science Virtual Shop" project (www.uxc.it), that re-uses the $\mathrm{CNs}$ culture to open up academic research to the vast public and to possible investors.

\section{Strategies for selecting revenue sources}

We don't believe any single source of income can - alone - fully support a CN. Even more, being completely funded either by a public body or by a private company (or, anyhow, by one single decision-maker) could be dangerous for the CN's independence. On the contrary, a variety of revenues deriving from different sources may assure the economic sustainability, while at the same time

\footnotetext{
${ }^{2}$ We mention also different types of labor contracts, even if they are strongly tied to the national market, to stress their importance in assuring a certain degree of flexibility, which helps a lot in handling different kinds of collaborations.
} 
preserving independence. Hence, RCM has exploited its core competences (in community building and managing) as a fundamental asset in the following mix of activities:

1) because of its significant expertise in developing (good quality) public services, RCM has often been involved in research projects and activities on e-participation, e-governance and edemocracy;

2) RCM's teaching activities have spread over several technical areas (from basic courses for introducing people to ICTs, to advanced courses for developing web applications and services mainly using Open Source software), as well as less technical ones. The targets of these activities, vary a lot as well, including local governments (RCM staff supports public employees in learning the fundamentals of Computer Mediated Communication - CMC, including legal aspects), and SMEs;

3) since the management of an integrated online environment such as a $\mathrm{CN}$ requires technical skills, a certain percentage of RCM's total income derives from more "techie" forms of consultancy (software development, technical specifications definition, technical evaluations, and from research and development activities in the ICT field; and

4) as communities and online communities are more and more seen as a resource for development (both in business and not-for-profit environments), RCM re-sells its "community expertise" in any project involving community services.

These activities usually lead to the development of further partnerships, assuring both fresh income sources and the possibility to exploit - in a synergistic way - marketing channels otherwise unreachable by a $\mathrm{CN}$.

However, it is fundamental to keep all the above activities as much as possible close to the community network mission, otherwise the danger of becoming a consultancy firm - as happened to the Amsterdam Digitale Stadt - may become very real.

\section{Strategies for selecting an appropriate institutional architecture}

A CN can build in different ways: by being promoted by a public body, or by a University, or by a private company rooted in a local area, or by a group of citizens, etc. However, we believe that its sustainability requires, after a period of activity, acquiring an autonomous status, able to guarantee its survival and independence: for RCM this happened after about three years of activity, when the RCM Participatory Foundation (FRCM) was born.

The choice of an appropriate institutional architecture depends on several considerations, including local issues and juridical constraints. It is out of the scope of this paper to discuss all the possible alternatives, nevertheless it is worth describing the major benefits RCM obtained from its institutional architecture:

- acquiring visibility and credibility, also (and especially) towards public bodies (such as the Chamber of Commerce) and local government;

- avoiding the constraints to which business players are subject, e.g. while accessing public funds and/or while stipulating consultancy contracts with public bodies;

- lowering personnel turnover, thanks to the possibility of directly managing contracts;

- maintaining privileged relations with the University, which in turn leads to the diffusion of an innovative approach among the staff members and as well supplies skilled personnel; and

- reducing the total cost of this management and overhead.

For us, the Participatory Foundation (see De Cindio, 2004) statute fits well with the needs of a CN, mainly for two reasons:

1. it is basically a non-profit form which can also be used in the market as a business subject: hence equally addressing both independence and economic survival; and

2. its hybrid characteristics enable the $\mathrm{CN}$ to play different roles with different components of the local community.

The FRCM statute also guarantees that each component of the local community could be represented in its board. Actually, local government organizations (the Region, the Province, the Chamber of Commerce and the University of Milan) are charter members: each of these having a representative on the board. Private companies can become supporting members and elect a 
representative to the board, as well. Finally, by becoming participants (simple members) of the foundation, citizens, non-profit associations and schools, as well as small and medium-sized enterprises, acquire the right to elect one representative for each 500 members.

However, the Participatory Foundation form also has several weaknesses:

1. in some Countries - including Italy - specific laws may generate fiscal problems, since percentages are strictly fixed (in Italy: 50\% and 50\%) for the tax fee portion of incomes generated by business activities and other non-profit sources (e.g. donations, membership fees, etc.);

2. in the RCM experience, despite several promotional campaigns, only very few community members (individuals, as well as schools and non-profit associations) have subscribed to become members of the Foundation ${ }^{3}$. Since they use the CN "for free", the awareness that this would be a way for guaranteeing the $\mathrm{CN}$ independence is not easy to convey;

3. it is not always straightforward to make the local governments accept the opportunity of supporting the $\mathrm{CN}$ (mainly because of the clashing relations between CNs and institutional web sites); and

4. due to the unfavorable market conjuncture, private companies who have agreed to become supporting members are supplying free goods or services (rather than donating money as they did a few years ago), while any other type of cooperation is based on shared projects formalized through contracts.

Despite these difficulties, it is likely that RCM would never have reached its tenth year of activity with any other institutional architecture.

\section{Conclusions and future developments}

The RCM case study supports the prototype model presented in paragraph two, highlighting that the sustainability of a CN cannot (and should not) be measured purely on a cost-revenues basis, for costs - if "directly measured" - exceed revenues. The prototype model presented here is a first attempt to overcome the lack of an appropriate model for assessing the economic sustainability of online communities. The approach here - through a cost-benefit analysis - supplies a way for considering the socio-technical factors which affect community sustainability but which may be overlooked in the framework of the more traditional and easy-to-understand cost-revenue approach. Actually, the output of the cost-benefit evaluation provided by our model supports the identification of strategies coherent with the goals of the community and thus helps assure its economic and financial sustainability. These strategies can be translated into actions aimed at producing revenues sufficient to cover costs. This holds true as well for CNs, which are not-for-profit organizations whose goal and mission concern the empowerment and welfare of a local community and therefore whose activity is supposed to be a form of commonly shared or public good.

Of course, the more general validity of the model should be further investigated, firstly for other $\mathrm{CNs}$, and then for other non-profit online communities, in this way deriving a well-defined set of guidelines possibly helpful for any non-profit online community. Similar empirical testing should be done in "for profit" online communities, in this way bringing to the surface differences and similarities between for and not-for-profit communities.

The RCM case study teaches a few "lessons" about how to build effective strategies for achieving the economic sustainability of a CN. Strategies to cover financial needs call for:

- $\quad$ selecting an effective institutional architecture (e.g. Participatory Foundation);

- containing costs through appropriate actions (e.g. developing partnerships);

- reinforcing performances by choosing activities (selected consultancy, teaching, etc.) coherent with the CN's goals and mission. This income should come from activities where the CN with respect to other public or private subjects - can put those competencies deriving from its core activities (e.g., participatory and universal design), to work as for example in supporting

\footnotetext{
${ }^{3}$ In January 2004 there were about one hundred participants-eight schools and six non-profit associations.
} 
ICT alphabetization for less advantaged people, and involving citizens in public service codesign processes.

These strategies should guarantee economic sustainability and cost coverage by balancing public funds, partnerships with public and private bodies and revenues coming from selected "market-like" activities.

Finally we remark that online communities are long term investments that require a lifecycle approach, for which the present work offers a prototype model for evaluating cost vs. benefits in a specific life stage (maturity), and, through the analysis of a snapshot of how the RCM case operates at the current moment in time, for deriving effective strategies. Nonetheless, a more accurate analysis of the dynamics of this case will be carried on in the future, to integrate more explicitly the time dimension into our conceptual model.

However, we do believe that the major need is to refine the definition of benefits and performance indicators (e.g. taking inspiration from Thompson, 1967). One of the main difficulties in measuring the benefits of an online community arises from the fact that at this moment no satisfying solution exists for tracking what is happening in an online socio-technical environment. Thus we believe that a major priority should be given to the design, implementation and testing first within RCM, (extending the work of: Longhi, 2000) of an appropriate set of monitoring tools (specific log files, statistic methods, etc.) which - while preserving people privacy - are able to derive from day-by-day online activities precise information about the number of active members, their main interests and activities, and the like. This information would be the basis for evaluating the actual benefits the community provides to its members, and for building effective performance indicators. 


\section{References}

Armstrong, A.G. and J.III Hagel (1998). Net Gain - creare nuovi mercati con Internet. Etas.

Carroll, J.M.and M.B. Rosson (2003). “A Trajectory for Community Networks” in: Sawhney H. (Ed.), Special Issue "ICTs and Community Networking", The Information Society International Journal, Vol.19, N.5, pp.381-393.

De Cindio, F. (2004). “The Role of Community Networks in Shaping the Network Society: Enabling People to Develop their Own Projects". In: Schuler, D. and Day, P. (Eds.) Shaping the Network Society. Cambridge, Mass.: MIT Press.

De Cindio, F., Gentile, O., Grew, P., and D. Redolfi (2003). "Community Networks: Rules of Behavior and Social Structure" in: Sawhney H. (Ed.), Special Issue "ICTs and Community Networking“, The Information Society International Journal, Vol.19, N.5, pp.395-406.

De Cindio, F. and L.A. Ripamonti (to appear). "Natures and Roles for Community Networks in the Information Society" Invited paper in AI \& Society special issue on "Community Informatics" P.Day (Ed.).

Fiol, C.M. and E.J. O’Connor (2002). When Hot and Cold Collide in Radical Change Processes: Lessons from Community Development. Organization Science, Vol.13, N.5, pp.532-546.

Kaplan R.S., and D.P. Norton (1996). Balanced Scorecard: Translating Strategy into Action. Harvard Business School Press.

Kim, A.J. (2000). Community building on the Web. Peachpit Press.

Lee, G.K. and R.E. Cole (2003). "From a Firm-Based to a Community-Based Model of Knowledge Creation: The case of the Linux Kernel Development”. Organization Science, Vol.14,N.6, pp.633-649.

Longhi, I. (2000). Strumenti per il monitoraggio di una comunità virtuale. Degree these in Informatics, University of Milan, Italy.

Lovink, G. and P. Riemens (2004). “A Polder Model in Cyberspace: The Contemporary Amsterdam Public Digital Culture.” In: Schuler, D. and Day, P. (Eds.) Shaping the Network Society Cambridge, Mass.: MIT Press.

Millen, D.R., Fontane, M.A., and M.J. Muller (2002). “Understanding the benefits and costs of communities of practice". Communications of the ACM, Vol.45, N.4, pp.69-73.

Orr, J.E. (1990). Talking about machines: an ethnography of a modern job. UMI.

Preece, J. (2000). Online Communities: Designing Usability, Supporting Sociability. Chichester, UK: John Wiley \& Sons.

Ripamonti, L.A. (2004). Online Communities of Practice for Knowledge Sharing in SMEs. Ph.D. thesis in Informatics, D.I.Co. University of Milan, Italy.

Thompson, J. D. (1967). Organizations in Action: Social Science Bases of Administrative Theory. New York: McGraw-Hill.

Venkatesh, M. (2003). “The Community Network Lifecycle: A Framework for Research and Action" in: Sawhney H. (Ed.), Special Issue "ICTs and Community Networking“, The Information Society International Journal, Vol.19, N.5, pp.339-347.

Von Hippel, E. (2001). "Innovation by User Communities: Learning from Open-Source Software". MIT SLOAN Management Review, summer 2001, pp.82-86. 
Wenger, E., R. McDermott, and W.M. Snyder (2002). Cultivating communities of practice - A guide to managing knowledge. Boston, MA: Harvard Business School Press. 